\title{
Movimento Lógico da Figura Hegeliana DO SENHOR E DO SERVO
}

\author{
André Oliveira Costa ${ }^{1}$ \\ Agemir Bavaresco ${ }^{2}$
}

\begin{abstract}
RESUMO: O presente artigo objetiva discutir a lógica subjacente ao movimento dialético da figura do Senhor e do Servo. Jean-Pierre Labarrière é quem afirma categoricamente a tese segundo a qual há uma Lógica por trás do movimento da Consciência. Ora, a questáo fundamental que se coloca, nesse caso, é: qual a lógica que preside o movimento da consciência para a consciência de si, culminado em sua unidade no momento da Razão? A hipótese aqui perseguida, situando-se na esteira da interpretação de Labarrière, é de que a lógica que se encontra "por trás da consciência", nessa figura da Fenomenologia do Espirito, é a mesma lógica que Hegel apresenta na Doutrina da Essência, na Ciência da Lógica. Para tanto, explicitar as categorias lógicas da Doutrina da Essência e acompanhar o seu desdobramento configuram o objetivo central deste trabalho.
\end{abstract}

PALAVRAS-CHAVE: Hegel. Labarrière. Lógica. Senhor e Servo. Reconhecimento. Doutrina da Essência.

\section{INTRODUÇÁO}

A figura do Senhor e do Servo é uma das mais conhecidas passagens da Fenomenologia do Espirito. Segundo Labarrière, o destaque que ela ganhou através da leitura marxista fez com que seu sentido fosse redimensionado dentro dessa obra e da própria Filosofia de Hegel. A retomada de Kojève igualmente ressignificou essa figura, aplicando, nessa luta entre duas autoconsciências, o sentido da gênese antropológica, de formação do homem em animal social e civilizado ou, nas palavras do autor, “[...] o homem só se confirma

1 Psicanalista. Mestre em Filosofia pela Pontifícia Universidade Católica do Rio Grande do Sul. Doutorando em Educação pela Universidade Federal do Rio Grande do Sul. E-mail: androlicos@ gmail.com

2 Doutor em Filosofia pela Universidade Paris I (Panthéon-Sorbonne). Professor de Filosofia da PUCRS. E-mail: abavaresco@pucrs.br . Site: www.abavaresco.com.br 
como humano se arriscar a vida (animal) em função de seu desejo humano" (KOJÈVE, 1947/2002, p. 14).

Tendo recebido uma multiplicidade de sentidos por diferentes comentadores, Labarrière e Jarczyk pretendem retomar essa figura do Senhor e do Servo, de modo a restituí-la no lugar onde ela se encontra dentro da Fenomenologia e do Sistema hegeliano. (LABARRIÈRE; JARCZYK, 1987, p. 23). Nesse sentido, eles a compreendem a partir do próprio conceito de "figura", isto é, um espírito incompleto ou o todo sob uma determinação. Cada figura encontra-se, em um determinado momento da obra, em função do sentido específico que ela assume com as figuras antecessoras e sucessoras.

A figura do Senhor e do Servo, segundo a leitura de Labarrière, tem seu sentido recolocado dentro da relação que ela mantém com o momento anterior, ou seja, o da verdade do objeto, para o movimento à verdade da certeza de si mesmo. Isso, entáo, indica que a autoconsciência é a verdade da consciência, de sorte que aquela se realiza plenamente nesta. Este é o movimento do percurso da consciência que vai do conhecer (erkenen) ao reconhecer (anerkennen), no qual o primeiro abrange as relaçóes da ordem do saber e o segundo as relaçóes presentes no próprio existir.

$\mathrm{Na}$ figura que antecede à do Senhor e do Servo, sobre o Desejo e a Vida, a consciência mantém uma dupla relação, a saber, com ela mesma e com o objeto do mundo. Ora, essas relaçóes apresentam o modo como se dá sua duplicação, de forma que o que lhe faz face não é senão ela mesma posta como outro. Conforme Labarrière, esse movimento é regido de acordo com o seguinte princípio: “[...] vindo 'fora de si', a consciência-de-si se perde ela mesma, se apercebendo como outra, ao mesmo tempo que ela perde também o outro, no lugar do qual ela se apercebe ela mesma” (LABARRIÈRE, 1979, p. 153).

Isso conduz a um duplo movimento, negativo e positivo. Movimento negativo, porque ela suprassume o outro, para se pôr em sua certeza; e ela se suprassume na medida em que este outro não é outro que ela. Movimento positivo, porque, suprimindo esse outro, ela se póe de novo como igual a ela mesma e, retirando-se do outro, ela o deixa existir por ele mesmo de forma autônoma. Assim, Labarrière decompóe em quatro formas desse relacionamento especular: a) "um fazer em relação a si”, b) "um fazer em relaçâo a outro", c) "um fazer do outro em relação a si” e d) "um fazer do outro em relação ao outro" (LABARRIÈRE, 1979, p. 154). 
Essas quatro operaçôes, assim, são transcritas para as seguintes estruturas relacionais: a) Sujeito sobre Sujeito; b) Sujeito sobre Objeto; c) Objeto sobre Objeto; e d) Objeto sobre Sujeito. Contudo, essa configuração mantém a regra de leitura da seção Consciência, na qual o sujeito ainda não se compreende refletido no objeto. Ora, sabemos já que o objeto é ele mesmo sujeito, o que leva à consideraçáo da posição na qual cada autoconsciência se situa uma diante do outra. Em decorrência, essa estrutura quádrupla é reescrita por Labarrière, de acordo com as seguintes denominaçóes: A e A', para designar cada uma das autoconsciências; e (s) e (o), para designar a função que elas assumem na relação. Desse modo, tem-se: a) "As sobre Ao", b) "As sobre A'o", c) "A's sobre A'o" e d) "A's sobre Ao" (Cf. LABARRIÈRE, 1979, p. 154).

Com isso, Labarrière focaliza a lógica de determinaçáo inicial da autoconsciência em seu movimento de formação através da relação com outra autoconsciência, sua alteridade subjetiva. O que cada uma das partes, enquanto sujeito, realiza com a outra, enquanto objeto, faz com que haja especularmente o mesmo movimento sobre ela mesma, de maneira que esses dois movimentos se tornem conjuntos.

A interpretação de Labarrière sobre a figura do senhor e do servo se sustenta na relação que se estabelece entre a Fenomenologia do Espírito com o Sistema filosófico de Hegel, particularmente com a Ciência da Lógica. Para o primeiro, é possível verificar uma "lógica por trás da consciência", na medida em que essas duas obras não podem ser consideradas independentemente, mas apenas uma em relação à outra. Isso permite que se identifique, por exemplo, na figura do senhor e do servo, os mesmos princípios organizadores de determinado momento da Ciência da Lógica.

Por conseguinte, afirmam Labarrière e Jarczyk: "Esta posição igual de uma diferença e de uma relação na qual cada um é a medida do outro é a escritura fenomenológica do movimento da reflexão, tal como ele se encontra exposto na Ciência da Lógica, no início da Doutrina da Essência” (LABARRIÈRE; JARCZYK, 1996, p. 75). Ora, esta é a proposta dos autores de ler na Fenomenologia o dinamismo que é o do Conceito abordado na Lógica em sua pureza.

Apresentaremos a seguir a compreensão de que a lógica que movimenta a experiência da autoconsciência nessa figura tem como princípio o movimento do pensamento na Doutrina da Essência, isto é, a reflexáo como um movimento interior de diferenciaçáo inicial entre fenômeno e aparência, 
mas que se configura, no decorrer do movimento do pensamento, uma mesma unidade diferenciada. Todo esse processo reflexivo da Essência na Ciência da Lógica se desenvolve pela mediação consigo mesmo, negando-se e retornando a si mesmo a essa identidade diferenciada.

A lógica da Essência, portanto, evidencia o movimento de diferenciação em uma alteridade que é constituída pela própria entidade, ou seja, de um ser que se mostra na Aparência em negação com sua Essência. A Aparência, pois, surge como a alteridade da Essência, mas posteriormente é considerada uma parte diferenciada desta. Da mesma forma, a autoconsciência desenvolve-se ao longo da figura do Senhor e do Servo, no sentido de que ela se duplica e se diferencia internamente, pondo uma outra autoconsciência como alteridade subjetiva diferente dela. Entretanto, essa relação se revelará como uma reflexão especular de uma identidade diferenciada, quer dizer, como uma estrutura unitária que possui a alteridade como diferença presente em seu interior, por meio do processo de reconhecimento.

Labarrière divide em três momentos esta seção "Independência e Dependência da Consciência-de-si: Dominação e Escravidão" (LABARRIÈRE, 1987, p. 150-167). Trata-se de uma figura organizada em 19 parágrafos, de acordo com a organizaçáo do tradutor Paulo Meneses. A primeira parte, que abrange do $\$ 178$ ao $\$ 184$, segue o "esquema lógico do reconhecimento", no qual se explicita a estrutura relacional das autoconsciências e as condiçóes para alcançarem o reconhecimento. O segundo momento, que vai do $\$ 185$ ao $\$ 189$, apresenta a "Luta de vida ou morte", em que se retorna ao início do esquema anterior, através de uma contradição. A terceira parte conclui os parágrafos finais dessa figura, $\$ 190$ ao $\$ 196$, por meio da relação do Senhor e do Servo, parte determinante dessa seção Autoconsciência.

A tradução de Herrschafft e Knechtschafft desvela divergências entre intérpretes de Hegel. Alexandre Kojève, por exemplo, traduz por Maîtrise e Servitude, remetendo essas posições para os sujeitos senhor (Maître) e escravo (Esclave), termos mantidos por Hyppolite, na tradução francesa da Fenomenologia. Labarrière posiciona-se contrário a esses termos. Este autor objeta que a tradução por "escravo" carrega uma carga ética e política que não se encontra ainda nessa figura da Fenomenologia. Da mesma forma, considera o termo Knecht mais próximo de "domesticidade", "vassalo", "serviçal”, com a dupla nuance de sujeição e proximidade familiar, visto que ele não permanece “[...] simplesmente dominado por uma angústia de morte, mas lhe é essencial exprimir este medo na transformaçáo do mundo pelo trabalho, entendido 
como uma forma de cultura - o que assume a esta figura uma qualidade positiva e criadora estranha à atitude do escravo" (LABARRIÈRE; JARCZYK, 1996, p. 71).

Segundo Labarrière e Jarczyk, não pode se tratar do termo "escravo", porque Hegel, em outras passagens de sua obra, usa explicitamente a palavra "Sklave" e não "Knecht". Esse termo - Knecht-é utilizado no corpo do texto dessa figura e no início da figura seguinte várias vezes para comentar a atividade do servo, juntamente com o vocábulo pertencendo ao verbo dienen (servir), o que constitui um argumento decisivo para legitimar, sob o ponto de vista terminológico, a relação interna entre servo (Knecht) e servir (dienen). Sob o ponto de vista hermenêutico, o servo, ao escolher romper o combate, dialetiza o medo de morte em trabalho transformador e em cultura emancipadora, o que constitui um serviço de luta criadora e não uma atitude da consciência submissa do escravo.

Dessa forma, assumiremos neste trabalho a tradução proposta por Labarrière em sua versão da Fenomenologia do Espirito para designar os termos de Hegel Herrschafft e Knechtschafft, e Herr e Knecht, como, respectivamente, dominação/servidão e senhor/servo.

\section{O ESQUEMA LÓGICO DO RECONHECIMENTO}

O primeiro parágrafo desse texto começa com o resultado ao qual a autoconsciência deve chegar para alcançar o reconhecimento: “[...] a consciência-de-si é em si e para si quando e por que é em si e para si para uma Outra; quer dizer, só é como algo reconhecido" (HEGEL, 1807/2003, $\$ 178$, p. 142). De início, está colocado o termo "reconhecimento", conceitochave para a compreensão da figura do Senhor e do Servo. Ele resulta do movimento simétrico e reversível que faz com que o reconhecimento leve à identidade do conhecedor e do conhecido, quer dizer, uma autoconsciência só pode ser o que ela é, se for reconhecida como tal, "[...] porque é bem da autoconsciência que aqui se tratará: um sujeito singular que é ele mesmo singular - apenas nesta duplicação interior que o revela como essencialmente relacional" (LABARRIÈRE; JARCZYK, 1987, p. 75).

A leitura de Labarrière e Jarczyk, seguindo a lógica própria da Doutrina da Essência, é de que a duplicação da autoconsciência não ocorre externamente, isto é, através do encontro com uma dualidade estrangeira, mas se trata de 
uma diferenciação interna em uma unidade de origem. Uma economia lógica, portanto, que se aproxima da lógica da Essência, na qual o ser se movimenta em direção a seu interior para a diferenciação entre Aparência e Essência.

Essa duplicação da autoconsciência, por conseguinte, segue o movimento da reflexão essencial que marca uma exterioridade de si na formação da alteridade. "Os momentos desta unidade plural - o ser em e para si da autoconsciência e seu ser-reconhecido por um outro - estão ao mesmo tempo um em relação ao outro em um estado máximo de diferenciação, e, nesta diferença mesma, reconhecidos como não diferentes." (LABARRIÈRE; JARCZYK, 1987, p. 77). O reconhecimento, desse modo, só pode ocorrer através de termos que são idênticos mas que mantêm entre si uma diferenciação, não enquanto grau de hierarquia e de subordinação, mas como um outro que pertence ao primeiro termo.

De acordo com Labarrière e Jarczyk, os parágrafos 179-181, expressando o início do desenvolvimento lógico do reconhecimento, estão encadeados nesse movimento do reconhecimento pelo silogismo das determinaçóes da reflexão: reflexão ponente (setzende Reflexion), reflexão exterior (äusserliche Reflexion) e reflexão determinante (bestimmende Reflexion). A autoconsciência, nessa duplicação dela mesma, em primeiro lugar, póe uma alteridade subjetiva, quer dizer, nesta saída fora de si ela póe um termo exterior por intermédio dessa diferenciação interior. "Para a consciência-de-si há uma outra consciência-desi [ou seja]: ela vai para fora de si” (HEGEL, 1807/2003, \$179, p. 143).

Coloca-se uma dupla relação com essa outra autoconsciência que lhe aparece: primeiro, a autoconsciência se perde, ao ver a outra como essência, porém, por outro lado, ela não vê a outra como essência, pois se vê a si mesma nessa outra. Esse vir para fora de si da autoconsciência, então, indica a formação exterior da essência de sua alteridade, ou seja, da duplicação essencial que caracteriza o processo de diferenciaçáo entre interior e exterior.

Retomando, portanto, a proposição inicial de condição de a existência da autoconsciência ser reconhecida para si, afirmam Labarrière e Jarczyk: “[...] a alteridade posta [...] revela a dimensão auto-reflexiva essencial da autoconsciência; uma auto-reflexão que, do fato desta reduplicação interior das mais reais, mostra-se nela mesma como isto que "autoriza" o reconhecimento efetivo” (LABARRIÈRE ; JARCZYK, 1987, p. 81). Nessa perspectiva, essa saída fora de si da autoconsciência póe uma duplicaçáo exterior a partir de sua duplicação interior. 
No $\$ 179$, há o movimento da reflexão ponente (setzende Reflexion) da essência na colocação deste outro da autoconsciência. Todavia, "[...] a consciência-de-si tem de suprassumir esse seu-ser-Outro" (HEGEL, $1807 / 2003$, \$180, p. 143), porque, na correspondência ao movimento do desejo, a negação do outro leva à negação de si mesmo. Esse suprassumir, logo, é aquele do primeiro sentido, o "da perda de si mesma".

Para suprassumir esse outro, a autoconsciência inverte os dois momentos anteriores. Ela suprassume a outra essência e volta com a certeza de si como essência; depois, porque a outra era vista como o reflexo de sua essência, a suprassunção dessa outra leva à suprassunção de si. Esse processo de suprassunção do "seu-ser-Outro" corresponde, segundo Labarrière e Jarczyk, ao momento da reflexão exterior (äusserliche Reflexion) da lógica da Essência. É o momento de colocar em questão que essa alteridade é realmente independente, quer dizer, "[...] para [a autoconsciência] ser ela mesma - ela o é apenas na medida onde ela se remete a um ser-outro autêntico -, é necessário entâo suprassumir este ser-outro seu enquanto que ele é de início apenas seu" (LABARRIÈRE; JARCZYK, 1987, p. 84).

Ora, para a autoconsciência ser ela mesma, ela deve suprassumir esse outro, o que acarreta na suprassunção de si e na manutenção da independência desse outro. Hyppolite enfatiza: "Enfim, ao pretender suprimir toda alteridade, o retorno completo do $\mathrm{Si}$, no fundo, só conduziria a deixar o Outro livre do Si [...] e, portanto, reconduziria à alteridade absoluta." Desse modo, o outro não é mais reflexo da autoconsciência, mas independente dela. Além disso, continua Hyppolite: “[...] nessa dialética [...] um ponto é essencial: a alteridade não desaparece” (HYPPOLITE, 1946/1999, p. 182). Ao suprassumir a outra, a autoconsciência volta a ser igual a si e faz a outra também voltar a si própria.

Dessa forma, deve-se colocar o terceiro momento da reflexão, aquele que diz a determinaçáo como o ponto de chegada do processo reflexivo. Assim, segundo Labarrière e Jarczyk, por esse motivo, coloca-se aqui o termo "retorno", igualmente presente no momento de determinação da reflexão: "Esse suprassumir de sentido duplo do seu ser-Outro de duplo sentido é também um retorno, de duplo sentido, a si mesma" (HEGEL, 1807/2003, $\$ 181$, p. 143). Um retorno que é sempre outro que o simples reinvestimento do primeiro momento, “[...] porque é apenas agora, devido a este processo reflexivo, que a origem se encontra posta e sabida como auto-desenvolvimento estrutural" (LABARRIÈRE; JARCZYK, 1987, p. 85). Dá-se, dessa maneira, a simetria necessária para a ocorrência do reconhecimento. 
Neste $\$ 181$, verificamos “[...] a união dos extremos, que se exprime aqui como o 'retorno' em si mesmo desta interioridade realmente exteriorizada” (HEGEL, 1807/2003, p. 80). Ora, se no primeiro momento a autonomia da autoconsciência deixava ao outro o lado da dependência, a dupla negação de si em seu outro e do outro como si resulta na conclusão de que essa alteridade também é uma autoconsciência. Assim, nas palavras de Hegel, a autoconsciência em seu movimento "[...] restitui também a ela mesma a outra consciência-de-si, já que era para si no Outro. Suprassume esse seu ser no Outro, e deixa o Outro livre, de novo" ( HEGEL, 1807/2003, \$181, p. 143).

Em consequência, está posta essa alteridade subjetiva. Trata-se de um "[...] movimento da consciência-de-si em relação a uma outra consciênciade-si”, de forma que não é o agir de uma autoconsciência sobre uma outra posta no lugar de objeto do desejo, "[...] porém esse agir de uma tem o duplo sentido de ser tanto o seu agir como o agir da outra; pois a outra é também independente, encerrada em si mesma, nada há nela que não seja mediante ela mesma” (HEGEL, 1807/2003, \$181, p. 143).

O que a consciência faz sobre a outra, esta também faz sobre ela. Abandona-se o unilateralismo do "agir de uma" dos momentos anteriores e se passa para a situação em que o "agir de uma tem duplo sentido." O que significa, segundo Labarrière e Jarczyk, "[...] que náo se trata de início do reencontro entre dois indivíduos separados, mas da qualificação reflexiva de toda autoconsciência em seu agir relacional" (LABARRIÈRE; JARCZYK, 1987, p. 87). Ocorre, dessa maneira, o que vimos na estrutura especular entre as autoconsciências em posicionamento subjetivado e objetivado. Desse modo, o que cada autoconsciência faz em direção a outra e a si mesma espelhase no agir da outra autoconsciência.

O \$183, então, apresenta essa quádrupla relação da autoconsciência e a outra autoconsciência idêntica do duplo agir de si sobre si e sobre o outro. Com essa caminhada da autoconsciência, suprassume-se a perspectiva do solipsismo subjetivo para aquela da subjetividade constituída através das relaçôes estabelecidas com outras subjetividades, mostrando que a autoconsciência é constitutivamente relacional. Como a autoconsciência já não se encontra mais no processo dinâmico do desejo, pois agora sua alteridade também espelha o elemento da dependência e independência, a autoconsciência já não tem mais o domínio natural sobre sua alteridade. 
$\mathrm{O} \$ 184$ fecha esse processo lógico do reconhecimento, que nos conduziu à estruturaçáo em quatro vetores da relação da autoconsciência com sua alteridade especular. Labarrière e Jarczyk frisam a característica condicionante entre as ações das autoconsciências para alcançar o reconhecimento mútuo, pois é requerido "[...] para um reconhecimento verdadeiro, uma concomitante e uma convergência do agir de um e do outro" (HEGEL, 1807/2003, \$181, p. 143). O reconhecimento, nesse momento, é o movimento incessante do agir idêntico de uma autoconsciência sobre a outra.

Esse jogo de relaçóes, por conseguinte, é o que faz da autoconsciência uma autoconsciência, quer dizer, uma unidade fundamental em duplicação. Assim como no Jogo de Forças, é esse movimento recíproco e "[...] essa troca de sua determinidade, e passagem absoluta para o oposto" que definem a autoconsciência. Tal é, portanto, o movimento efetivo do reconhecimento: “[...] cada extremo é para o Outro o meio-termo, mediante o qual é consigo mesmo mediatizado e concluído; cada um é para si e para o Outro, essência imediata para si essente; que ao mesmo tempo só é para si através dessa mediação" (HEGEL, 1807/2003, \$184, p. 144).

Sustentando-se no silogismo da autoconsciência e sua alteridade especular, pôe-se a asserção inicial dessa figura na qual cada autoconsciência reconhece a outra e é reconhecida em si mesma, na medida em que a outra a reconhece e se reconhece como tal. Dessa forma, Hegel termina esse parágrafo com a situação ideal do reconhecimento: "Eles se reconhecem como reconhecendo-se reciprocamente."

\section{A luta de Vida ou MORTE}

Com o $\$ 185$, inicia-se a segunda parte dessa figura. Se até o momento foi tratado o conceito de reconhecimento em sua pureza lógica, a partir dessa segunda parte verifica-se a aplicação desse movimento na experiência fenomenológica.

Para a autoconsciência, esse processo de duplicação dela mesma em sua unidade começa pela desigualdade posta entre dois termos: "[...] um extremo é só o que é reconhecido; o outro, só o que reconhece" (HEGEL, $1807 / 2003$, \$185, p. 144). A situação perfeita para o reconhecimento destacada anteriormente, a saber, as autoconsciências reconhecem-se como se reconhecendo reciprocamente, é o resultado de um processo de negação que 
tem como ponto de partida a desigualdade desses termos, na qual se verifica a assimetria entre o agir de uma autoconsciência sobre o agir da outra.

O início do processo, pois, é o de uma autoconsciência como "serpara-si simples, igual a si mesma mediante o excluir de si todo o outro." Como retomada de um processo logicamente anterior, esse "simples" indica o estado de exclusão e negação da autoconsciência frente a sua alteridade. Isso quer dizer que, nesse momento, ela se apresenta em sua "[...] igualdade consigo por exclusão do outro, apreensão de si como essência e de toda outra realidade como inessencial. Imediatidade, ser, singularidade, individualidade, autonomia (sem inautonomia), consciência (sem autoconsciência), certeza (sem verdade)" (LABARRIÈRE; JARCZYK, 1987, p. 94). A autoconsciência parte da absoluta identidade a si, da "auto-suficiência não-relacional", sem duplicação na alteridade, de modo a fechar-se sobre si mesma.

"Mas o Outro é também uma consciência-de-si; um indivíduo se confronta com outro indivíduo" é a frase que relembra que a regra de leitura dessa seção é a da relaçáo dela consigo mesmo como outra autoconsciência. Estamos já no processo de duplicação da autoconsciência, mas ainda no momento em que ela se reflete pondo o outro como diferente. Assim, tratase da reflexão ponente (setzende Reflexion) que coloca a diferença interna na unidade, de sorte que a alteridade não é aqui percebida como alteridade especulativa, mas como um objeto comum. Cada termo da relação, portanto, está inserido ainda na lógica do desejo como Vida, e cada um é para o outro um objeto independente e inessencial, pelo qual "[...] o outro não é ainda ser de alteridade, porque a relação da consciência consigo mesma permanece massiva, in-diferenciada e não é verdadeiramente uma relação" (LABARRIÈRE; JARCZYK, 1987, p. 95).

As autoconsciências, dessa forma, ainda não podem ser uma para outra, porque ainda não se apresentaram como ser-para-si, que extirpou todo ser imediato. Nesse sentido, “[...] cada uma está certa de si mesma, mas não da outra; e assim sua própria certeza de si não tem verdade nenhuma, pois sua verdade só seria se seu próprio ser-para-si lhe fosse apresentado como objeto independente" (HEGEL, 1807/2003, \$186, p. 145). Para o reconhecimento, é necessário que a consciência aproxime sua certeza da verdade, isto é, que ela possa fazer a "pura abstração do ser-para-si" que a torna independente dessa imediatidade do ser da Vida e de sua alteridade objetiva. 
A condição para o reconhecimento novamente é posta por Hegel no fim desse $\$ 186$ : cada termo da relação deve ser um para o outro e cada um em si mesmo, por meio de seu próprio agir e do agir do outro. No segundo momento dessa parte, que trata sobre a "luta de vida ou morte", o outro se evidencia como uma autoconsciência. Dá-se o encontro direto entre as autoconsciências, dito melhor, de uma relação com uma alteridade exterior que é, para-nós, a justaposição especular da alteridade interior.

Entretanto, elas ainda não se apresentam uma a outra como autoconsciências. A condição para isso é negar a outra autoconsciência, demonstrando que "[...] não está vinculado a nenhum ser-aí determinado [...] nem à vida”, através da qual se tornaria ser-para-si. Mas, como estamos no momento reflexivo propriamente, qualquer movimento unilateral vai ser respondido igualmente no outro termo da relaçáo como um agir duplicado.

Conforme vimos na apresentação do esquema lógico do reconhecimento, o agir duplo é aquele não apenas sobre si mesmo, mas também sobre o outro, e deste igualmente sobre o primeiro. Mesmo que para nós estejamos tratando sobre duas autoconsciências, para cada uma, o outro ainda é visto como objeto e não como sujeito. Coloca-se em jogo, no momento, essa dependência da autoconsciência sobre o mundo natural. Mais do que um encontro facea-face entre as autoconsciências, trata-se de um encontro costa-a-costa (LABARRIÈRE; JARCZYK, 1987, p. 98), no qual “[...] cada um tende, pois, à morte do Outro."

A fim de negar essa imediatidade com o ser da Vida e sua dependência a ele, a autoconsciência busca a morte do outro. Nesse vetor, onde cada uma age em si e sobre a outra, continua Hegel, "[...] o agir por meio de si mesmo, pois aquele agir do Outro inclui o arriscar a própria vida. Portanto, a relação das duas consciências-de-si é determinada de tal modo que elas se provam a si mesmas e uma a outra através de uma luta de vida ou morte" (HEGEL, $1807 / 2003$, $\$ 187$, p. 145). A autoconsciência, colocando a vida do outro em risco, tem reflexivamente também a sua própria vida colocada em risco.

$\mathrm{O}$ agir dela sobre outra leva, dessa maneira, a exercer esse mesmo agir sobre si mesma. Como já está posto o elemento reflexivo nesta relação, tudo que ocorre da autoconsciência retorna a ela. Entretanto, "[...] esta reflexão, porque ela engendra uma exclusão - o ser-para-si se situando à margem do momento especulativamente coextensivo do ser-fora-de-si - não saberia produzir, aqui e agora, um 'reconhecimento' autêntico' (LABARRIÈRE; JARCZYK, 1987, p. 
101). Porém, a certeza de sua autonomia frente a essa relação imediata com os objetos deve ser transformada em verdade e, para isso, a autoconsciência como ser-para-si puro deve desligar-se dessa determinação objetiva imediata.

Esse combate de vida ou morte representa, nessa perspectiva, a necessidade da autoconsciência em desligar-se dessa dependência das determinaçóes imediatas. Essa luta, entấo, é uma atitude que, nesse momento, é a única possibilidade de alcançar a verdade que é a sua independência. Renunciar à luta de vida ou morte, por sua vez, seria deixar de ser reconhecida como autoconsciência independente, pressupondo que seria possível tornar-se independente excluindo, nessa relação com o outro, o movimento coextensivo de independência e dependência.

A morte, assim, não é uma escolha possível para que a autoconsciência consiga elevar a certeza de si mesma à verdade. Ao desligar-se da vida imediata, ela pode conduzir à negatividade pura, quer dizer, "[...] essa comprovação por meio da morte suprassume justamente a verdade que dela deveria resultar, e com isso também [suprassume] a certeza de si mesmo em geral" (HEGEL, 1807/2003, \$188, p. 146). A morte, portanto, seria a negação dessa vida imediata e não acederia a autoconsciência à vida espiritual, mas a manteria no unilateralismo e independência próprios da consciência.

Segundo Labarrière, essa passagem de um estado de unilateralidade da consciência ao de relacionamento reflexivo com sua alteridade subjetiva, nesse encontro de exclusão com outra autoconsciência, é "[...] análoga à exclusão que, de um ponto de vista lógico, parece pôr a essência à parte do ser do qual ela provém" (LABARRIÈRE; JARCZYK, 1996, p. 77). Em ambas as ordens, isto é, a fenomenológica e a lógica, continua o autor, “[...] é necessário ser afirmado, em sua estrutura reflexiva própria, que o termo novamente posto (a autoconsciência, a essência) é exposto à falta da verdade da relação a esta “exterioridade” na qual ele procede" (LABARRIÈRE; JARCZYK, p. 77).

Assim, se na passagem do Ser à Essência, aquele, ao interiorizar-se em direção a si mesmo, mostra-se fora dele como aparência, que, "[...] no primeiro tempo, só pode ser percebido como signo da não-reflexividade momentânea da essência" (LABARRIÈRE; JARCZYK, p. 77), no âmbito fenomenológico, o que a autoconsciência encontra frente a ela é uma outra autoconsciência em perfeita simetria em relação a ela, que só pode lhe aparecer como um desafio absoluto, uma ameaça de sua própria vida. 
Dessa negação sobrevive uma positividade através desse triplo movimento de suprassunção: negar, conservar e elevar. A posição da autoconsciência que enfrentava na luta pela vida ou morte a tentativa de negação de seu ser da Vida passa a uma nova postura, contudo, numa assimetria entre os termos desse silogismo.

Temos, dessa forma, o que vimos no primeiro parágrafo dessa figura como surgimento da diferença na essência da autoconsciência: "[...] o duplo sentido do diferente reside na [própria] essência da consciência-de-si”. Da dissolução daquela unidade simples da autoconsciência, póe-se a diferença de dois termos constitutivos de uma mesma unidade: "[...] uma pura consciênciade-si, e uma consciência que não é puramente para si, mas para um outro, isto é, como consciência essente, ou consciência na figura da coisidade" (HEGEL, $1807 / 2003$, \$189, p. 147). Uma posição que teve medo da morte não negou a relaçáo imediata com o ser da Vida e continua como ser-para-si simples em relação ao objeto comum. Trata-se da posição do servo, que descobre sua essencialidade na coisidade e se fixa nela. Outra posição da autoconsciência alcança a independência pela negação do elemento da Vida, eleva-se sobre as determinaçôes do mundo natural. Trata-se da posição do senhor.

\section{A Reflexáo na figura do SENHOR E do SERVo}

\section{RETOMADA DA “LÓGICA POR TRÁS” DA ALTERIDADE SUBJETIVA}

Nossa hipótese, acompanhando a leitura de Labarrière, é de que a lógica que se encontra "por trás da consciência", nessa figura da Fenomenologia, é a mesma lógica que Hegel apresenta na Doutrina da Essência, na Ciência da Lógica.

Ora, a lógica da Essência tem na reflexão seu movimento principal. Trata-se do movimento dividido em três determinaçôes, a saber, a reflexão ponente (setzende Reflexion), a reflexão exterior (äusserliche Reflexion) e a reflexão determinante (bestimmende Reflexion). Consiste no momento lógico em que o Ser se volta a si mesmo e se encontra ao mesmo tempo vinculado com o ser imediato e com algo que lhe é extrínseco. Verifica-se, assim, uma duplicação interna que póe na unidade a diferença entre interior e exterior. Essa diferenciaçáo interna constitui, como vimos anteriormente, um outro a partir de si mesmo. Esse desdobrar-se resulta na primeira oposição da Essência, a saber, entre a aparência e a essência. De uma unidade imediata do Ser, passamos a sua 
diferenciação interna que pôe a aparência como oposição da essência. De um momento imediato, passamos ao momento mediado da reflexáo.

A primeira diferenciação da Essência, nesse sentido, é a aparência, que é determinada como sua negação. Não se configura, porém, como um outro externo à Essência, mas é uma diferenciação dela mesma em uma unidade. $\mathrm{O}$ que se revela como aparência, então, vai ser descoberto como sendo a reflexão da essência mesmo. Se, nessa diferença, a Essência assume a determinação de independência, pois ela se mantém mediada consigo mesma, a aparência, por sua vez, vai ser assumir a dependência, porque se apresenta inicialmente como o negativo da Essência e sua manifestação exterior. No final do processo da Essência, a reflexão vai retornar completamente a si mesma, de modo que todo o reflexo sobre o outro será por identidade uma reflexão sobre si mesmo. Isso, porém, só será alcançado na Doutrina do Conceito.

Ora, seguindo o percurso da autoconsciência em sua manifestação fenomenológica, compreendemos como seu princípio regulador as mesmas determinações da Essência. Já nos coloca Hegel essa aproximação, no primeiro parágrafo da figura do Senhor e do Servo: a autoconsciência é uma "[...] unidade em sua duplicação" que tem seus momentos "rigorosamente separados, e de outra parte, nessa diferença, devem ser tomados ao mesmo tempo como nãodiferentes" (HEGEL, 1807/2003, \$186, p. 144). No início da figura, vemos uma autoconsciência que é idêntica a si mesmo e independente frente a sua alteridade que vinha da figura da Vida. Desse modo, temos a passagem da lógica própria do Ser, através da relaçáo da autoconsciência com seu objeto de desejo:

[...] de início, a consciência-de-si é ser-para-si simples, igual a si mesma mediante o excluir de si todo o outro. Para ela, sua essência e objeto absoluto é o Eu; e nessa imediatez ou nesse ser de seu ser-para-si é [um] singular. O que é o Outro para ela, está como objeto inessencial, marcado com o sinal do negativo. Mas o Outro é também uma consciência-de-si; um indivíduo se confronta com outro indivíduo. (HEGEL, 1807/2003, \$186, p. 144).

Esse agir duplo, porém, é duplicado no agir sobre si mesmo. O que ocorre sobre essa alteridade subjetiva que é uma aparência também ocorre sobre si mesmo. Este corresponde ao movimento da Doutrina da Essência da reflexão ponente (setzende Reflexion), que é o movimento de pôr a aparência como um outro de si mesmo. A Essência, por sua vez, fica como o momento da igualdade consigo mesma, que tem o elemento negativo. Não obstante, 
o movimento da reflexão ponente (setzende Reflexion) é de pôr um outro negativo de si, inessencial, e, dessa alteridade, retornar a si mesma.

Mas esse outro da aparência do ser-posto é a fusão ou a igualdade consigo mesma da Essência. Nessa reflexão, portanto, ainda não está posta efetivamente a alteridade. Essa passagem sobre a luta de vida ou morte é a primeira tentativa de realizaçáo da estrutura do reconhecimento apresentada em sua forma lógica pura. O reconhecimento, nessa passagem, não ocorre, por conseguinte, porque cada autoconsciência "[...] está certa de si mesma, mas não da outra; e assim sua própria certeza de si não tem verdade nenhuma" (HEGEL, 1807/2003, \$186, p. 145).

A reflexão ponente (setzende Reflexion) mostra a identidade frente à diferença, conforme Hegel a apresenta na Ciência da Lógica, "[...] não para não ter nenhuma diferença, mas para se comportar frente a esta como idêntica consigo mesma” (HEGEL, 1812/1968, p. 368). A passagem sobre a reflexão exterior (äusserliche Reflexion) vai ser determinante para que esse outro caracterizado como identidade possa ser compreendido como uma alteridade diferente. Para isso, fenomenologicamente, a autoconsciência deve passar pela luta de vida ou morte, ou seja, essa luta é a volta a si da reflexão ponente (setzende Reflexion) que suprassume a sua própria essência e a da alteridade. Ora, a reflexão exterior (äusserliche Reflexion) vai ser o momento em que o outro é visto como essencial e exterior, quer dizer, é independente por si mesma.

Conforme Labarrière e Jarczyk, é na Doutrina da Essência ou, mais precisamente, nessa reflexão exterior (äusserliche Reflexion), que "[...] o verdadeiro estatuto lógico da alteridade se decide neste nível" (LABARRIÈRE; JARCZYK, 1996, p. 91ss). Entramos, então, propriamente no momento da figura do Senhor e do Servo. Portanto, após o momento de identidade da autoconsciência como ser-para-si simples, passamos ao momento da diferença através dos termos opostos do senhor e do servo.

Com o $\$ 190$ da Fenomenologia, começa propriamente a figura da dominação e da servidão. O resultado da luta de vida ou morte é duas autoconsciências opostas que se reposicionam frente a seu outro nesta dialética que ocorre em uma unidade que é diferenciada internamente. Essa última parte da seção "Independência e Dependência da consciência-de-si" divide-se em dois momentos. No primeiro, entre os $\$ 190$ e $\$ 193$, é abordado o ponto de vista do senhor. Do $\$ 194$ ao $\$ 196$, por sua vez, é abordado o ponto de vista 
do servo, visto como o "[...] lugar de afirmação possível de uma autonomia verdadeira” (LABARRIÈRE; JARCZYK, 1987, p. 108).

\section{A LÓGICA DA REFLEXÃO NA EXPERIÊNCIA DO SENHOR}

Logo de início, Hegel coloca os termos dessa dialética, a saber, o senhor, em sua posição de domínio, o servo e a coisidade do mundo, que alternadamente assumem a posição de outro e de meio-termo da relação. Assim, escreve Hegel: "O senhor se relaciona com estes dois momentos: com uma coisa como tal, o objeto do desejo, e com a consciência para a qual a coisidade é o essencial" (HEGEL, 1807/2003, \$190, p. 147). Nesse sentido, temos as seguintes posiçóes do senhor: é um ser-para-si sem mediação, como conceito de autoconsciência, e é um ser-para-si, que só é mediante sua relação com um outro (coisa ou servo).

Igualmente essa relação com um outro é duplicada entre imediata e mediata, quer dizer, é uma relação imediata com o servo e a coisa, ao mesmo tempo em que é uma relação com ambos, um por meio do outro. Temos, inicialmente, uma dupla atitude do senhor: primeiro, em sua certeza simples de autonomia absoluta e, segundo, na verdade que passa pelo reconhecimento de um outro igual a ele mesmo. A primeira "[...] é o resíduo da abstração primeira da qual nós partimos, e sua passagem ao ato, sempre possível, seria a destruição pura e simples de um ou de outro [...] dos objetos a qual ele se relaciona” (LABARRIÈRE; JARCZYK, 1987, p. 109). A experiência seguirá a segunda atitude do senhor, que se mediatiza duplamente com um outro em busca do reconhecimento.

Hegel prossegue o texto, apresentando dois silogismos como resultados dessa relação da mediação do senhor: "[...] o senhor se relaciona mediatamente com o escravo por meio do ser independente" (a coisa) e "[...] o senhor também se relaciona mediatamente por meio do escravo com a coisa" (HEGEL, 1807/2003, $\$ 190$, p. 147ss). Temos, em decorrência, a seguinte sequência de relaçóes: a) "senhor $\rightarrow$ coisa $\rightarrow$ servo" e b) "senhor $\rightarrow$ servo $\rightarrow$ coisa". A primeira indica que o servo está preso à coisa, pois não abdicou dela na luta por vida ou morte, mostrando-se dependente dela, assim como revela que o senhor domina o servo através da coisa. Este, segundo Hegel, é o silogismo da Dominação.

O segundo silogismo evidencia que o servo se relaciona negativamente com a coisa, ou seja, ele a suprassume; não a destrói, mas a trabalha. O resultado 
desse trabalho sobre a coisa serve para a satisfação do desejo do senhor, que se transforma em gozo. A coisa, então, tem dois lados em sua relação com o senhor e o servo. Para aquele, ela é dependente e por isso pode ser destruída; para este, ela deve ser independente, já que sua destruição levaria à anulação de sua escolha sobre a Vida e, dessa forma, ela deve ser trabalhada.

Conforme aponta Hegel, nesse momento, apenas para o senhor vem a ocorrer o reconhecimento mediante a autoconsciência do servo. Em ambos os silogismos vistos, o servo póe-se como a parte inessencial, de modo que não pode nem satisfazer-se com seu próprio desejo ("alcançar a negação absoluta"), nem pode dominar a coisa ("assenhorar-se do ser") frente ao monopólio do senhor sobre ela. Não é possível, portanto, o reconhecimento nesse nível do percurso da consciência. A parcialidade e desigualdade da independência em face da impossibilidade de o servo tornar-se independente não permitem que o reconhecimento seja estabelecido como simetria de relação. O que ocorre, então, é um "reconhecimento unilateral".

Ora, chegamos a um impasse nessa relação de reconhecimento que se estabeleceu até o momento. O senhor, em sua busca pela independência, tem na autoconsciência inessencial (a do servo) "[...] o objeto que constitui a verdade da certeza de si mesmo" (HEGEL, 1807/2003, \$192, p. 149). De fato, sendo esta a sua verdade, ele torna-se diferente de uma autoconsciência verdadeiramente independente, pois deve essa condição à mediação do servo, que tem sua essência na coisa. O servo é dependente, porque escolhe a relação com um ser imediato e independente, que é a coisa provinda da figura da Vida e que foi negada pelo senhor. Logo, o servo é uma autoconsciência inessencial e dependente. A verdade do senhor se subordina a uma autoconsciência dependente, que, no momento, é incapaz de realizar a mediação reflexiva que é requerida para o reconhecimento.

Como estamos em um percurso da consciência organizado pela lógica reflexiva, veremos, nos próximos parágrafos da Fenomenologia, a resposta do servo a essa situação de dominação e a busca pela verdade do reconhecimento da autoconsciência. Se a dominaçáo, de início, impunha-se como a certeza da independência, a servidão, igualmente de início, vai se mostrar assim. "Primeiro, para a consciência escrava, o senhor é a essência; portanto, a consciência independente para si essente é para ela a verdade". Isso indica que o servo vai iniciar seu percurso buscando sua verdade fora de si, ou seja, no senhor. Trata-se, por consequência, desse primeiro momento necessário para o processo reflexivo da autoconsciência, em que se verifica a passagem do 
movimento de indiferenciação para o de reflexão de si mesmo no outro. O servo, entretanto, não vai buscar colocar-se na posição de senhor, porque esta foi uma experiência enganadora da verdade.

\section{A LOGICA DA REFILXXO NA EXPEREENCCA DO SERVO}

Com o \$194, surge uma nova perspectiva dessa busca pelo reconhecimento, agora na personagem do servo. Visto que a vontade do senhor resulta no contrário daquilo que ela propóe, o servo deverá tornar-se o contrário daquilo que ele é, ou seja, deverá alcançar uma verdadeira independência afastada da unilateralidade. Não se trata, nessa experiência do servo, de uma posição contrária a do senhor, como uma antítese do unilateralismo, mas da reformulação dessa estrutura parcial de reconhecimento.

$\mathrm{Na}$ posição que o servo assumia na lógica de relação de dominação, a essência do servo era constituída por esse seu modo de ser servil. Como autoconsciência que escolheu estar presa ao ser-aí natural, o servo carrega em si a submissão à dominação do senhor e a dependência sobre a própria coisa. $\mathrm{O}$ que fez, então, que assumisse essa postura foi a proximidade com a experiência angustiante do senhor absoluto, ou seja, a morte. Através dessa angústia frente à morte, o servo pôde deparar-se verdadeiramente com a possibilidade de seu desaparecimento total. A morte, consequentemente, retorna nesse momento com outra significaçáo daquela que levou à escolha no encontro com a alteridade subjetiva. Por causa dessa condição permanente ao longo dessa experiência, a autoconsciência servil "[...] se dissolveu interiormente; em si mesma tremeu em sua totalidade; e tudo o que havia de fixo, nela vacilou" (HEGEL, 1807/2003, \$194, p. 149). Esse medo da morte é, pois, elemento fundamental para o desenvolvimento do percurso próprio do servo.

Por intermédio desse medo da morte, a consciência consegue afastar-se de sua ligação com o mundo natural, resolver a luta entre os desejos e tornar-se autoconsciência subordinada ao senhor. Todavia, esse medo, por manifestarse na experiência do servo como angústia em relação à integralidade de sua existência, permite que essa autoconsciência tome conhecimento de sua verdadeira essência e, dessa forma, se desenvolva como puro ser em-si-e-parasi. Por isso, afirma Hegel: "[...] esse movimento universal puro, o fluidificarse absoluto de todo o subsistir, é a essência simples da consciência-de-si, a negatividade absoluta, o puro ser-para-si, que assim é nessa consciência" (HEGEL, 1807/2003, \$194, p. 149). Nessa perspectiva, a autoconsciência 
só pode formar-se em sua verdade, se ela passar pela angústia de dissolução de toda as suas determinaçóes essenciais.

Ora, o senhor não teve medo da morte e náo arriscou sua vida para assumir uma posição superior, de forma a eliminar de si o elemento objetivo da vida natural. $\mathrm{O}$ medo pelo qual passou o servo, entretanto, possibilitou que ele se deparasse com um princípio de realidade que o colocou em oposição ao processo de gozo do senhor sobre as coisas. O senhor, então, fez como escolha uma posição egoísta, ao manter sob domínio todas as coisas de acordo com seu desejo. O servo, por sua vez, ao passar pelo temor da morte, afasta-se dessa universalidade do reconhecimento parcial do senhor. Entretanto, se é pelo trabalho que o servo "suprassume em todos os momentos sua aderência ao ser-aí natural", é pelo trabalho que ele elimina essa condição. Vemos, por conseguinte, que o trabalho eleva o servo de sua posição individual e singular para a posição de autoconsciência universal, conservando, porém, esse momento de singularidade.

"Mas a consciência escrava é consciência-de-si, e importa considerar agora o que é em si e para si mesma” (HEGEL, 1807/2003, \$194, p. 149). Para ser autoconsciência reconhecida, o servo deve manifestar esse aspecto em si e para si. Como autoconsciência que possui a "negatividade pura", o servo é ser-para-si. Ele ainda não realizou para si essa independência verdadeira na condição de em-si-e-para-si, porque ela não pode ser efetivada por um trabalho servil a outra autoconsciência, mas apenas por um trabalho formador. O trabalho passa a assumir destaque na experiência da autoconsciência servil. Ao longo dos dois últimos parágrafos dessa figura, o trabalho vai resolver especulativamente as unilateralidades que prendiam o servo nos silogismos com a coisa e com o senhor. Todavia, o servo precisa realizar para si a "potência absoluta" que surgiu através da angústia da morte e da dissolução de sua estrutura interior. A objetividade dessa capacidade de realizar o reconhecimento é o que vai tornar o servo uma autoconsciência em-si-e-para-si e ser visto como uma verdadeira autoconsciência.

O senhor satisfazia completamente seu desejo com o trabalho do servo, negando no gozo a existência da coisa. O servo, por sua vez, colocava-se como a autoconsciência inessencial em função da independência da coisa e ao domínio do senhor. Nas palavras de Hegel: "Mas essa satisfação é pelo mesmo motivo, apenas um evanescente, já que lhe falta o lado objetivo ou o subsistir. O trabalho, ao contrário, é desejo refreado, um desvanecer contido, ou seja, o trabalho forma” (HEGEL, 1807/2003, \$195, p. 150). O trabalho, portanto, 
revela-se como meio-termo na dissolução alienante do silogismo entre o servo e a coisa.

Pela escolha de ser mediado pelo servo na relação com a coisa, o senhor utilizou-se do gozo como forma de dissolução do objeto, mas que não lhe trouxe subsistência para formar sua estrutura em si mesma permanente. Para o servo, entretanto, verifica-se que o trabalho vai transformar a coisa, de modo a produzir uma identidade, que é essa permanência, na diferença.

O trabalho não permite a continuidade alienante da dominação, mostrando que a independência só pode vir do resultado do "agir formativo", [...] "que agora no trabalho se transfere para fora de si no elemento do permanecer” (HEGEL, 1807/2003, \$195, p. 150). Isso indica que a transformação da coisa pelo servo não apenas imprime nesta suas determinaçóes, porém, constitui subsistência e permanência ao ser-para-si do servo. O reconhecimento do servo encaminha-se para o jogo especular que faz da independência da coisa a reflexão de sua própria condição. O ser-para-si do servo, dessa maneira, une-se ao ser-em-si da coisa. "O trabalho é, então, o que dá a este ser-para-si uma permanência no mundo humano" (LABARRIÈRE; JARCZYK, 1987, p. 123).

No último parágrafo dessa figura, vemos a dissolução desse percurso de oposição entre o senhor e do servo e o seu resultado na transformação realizada pelo trabalho formador. Nesse $\$ 196$, veremos como se resolve parcialmente a condição de reconhecimento, de modo a trazer à luz uma nova etapa da consciência. A lógica que se desenvolve nesse último momento é aquela que identifica em uma unidade a "interioridade essencial da consciência" com a "exterioridade do ser imediato", seguindo o movimento lógico da reflexão exposto na Doutrina da Essência da Ciência da Lógica.

Retomando o percurso da figura do Senhor e do Servo, vemos que o servo teve sua primeira relação com o senhor, de sorte que a essência deste estava fora de si, ou seja, um outro como. "No senhor, o ser-para-si é para o escravo um Outro, ou seja, é somente para ele." Através da experiência de medo da morte, o servo compreendeu que sua dominação não estava na figura do senhor, mas era a dominação da morte sobre sua própria essência total. O trabalho formando a coisa, por sua vez, propicia que o servo se imprima verdadeiramente nela, pois esta passou a ser uma maneira dele domesticar essa morte que vinha a ele do exterior. "No formar, o ser-para-si se torna para ele como o seu próprio, e assim chega à consciência de ser ele mesmo em si e para 
si." O trabalho formador, penetra no elemento subsistente, possibilitando com que a autoconsciência intua a sua própria independência. A autoconsciência trabalhadora, que já não está mais na relação de oposição servo/coisa, portanto, surge como a suprassunção dessas duas personagens, do ser-em-si e do serpara-si, que é apreendido pela negação desse ser-para-si estranho.

Nesse sentido, o objeto trabalhado "[...] náo se torna um outro que a consciência pelo fato de se ter exteriorizado" (HEGEL, 1807/2003, \$196, p. 151), uma vez que ele é precisamente o ser-para-si da autoconsciência trabalhadora. Esta, efetivamente, é capaz de se reconhecer nas coisas do mundo as quais trabalhou. Pelo trabalho, então, a autoconsciência consegue "[...] reencontrar-se de si por si mesma" na coisa, transformando isto que lhe era estranha e tinha um "sentido alheio" a ter "sentido próprio".

Segundo Hegel, para que tal reflexão possa ocorrer, são necessários dois momentos: o momento do medo e do trabalho, e também o momento da formação. $\mathrm{O}$ medo e o trabalho são dois elementos que náo levaram por eles mesmos a autoconsciência à condição do verdadeiro reconhecimento.

Em oposição à leitura marxista de Kojève, portanto, que compreende certa inversão da posição do servo em relação à posição do senhor e a vitória daquele sobre este, Labarrière afirma que o servo "[...] não toma o lugar do senhor, como se tratasse simplesmente de reverter, sem verdadeiramente anular, uma injustiça ética." (LABARRIÈRE; JARCZYK, 1996, p. 126) O trabalho, assim, não é uma maneira, segundo esse autor, de fugir do medo e da dissolução de suas determinaçôes, mas é o que, conjuntamente com esses dois movimentos, permite a saída de uma obstinação que "[...] faria do servo um simples alter ego do unilateralismo do senhor: onde prevaleceria uma inversão plana, sem nenhuma mediação" (LABARRIÈRE; JARCZYK, 1996, p. 127).

\section{Conclusão}

Apresentamos o desenvolvimento das experiências da autoconsciência nas posiçóes do senhor e do servo pela busca do reconhecimento. No final dessa figura, encontramos uma autoconsciência que não está propriamente em nenhum dos termos dessa primeira relação de reconhecimento, mas o que se origina é uma união desses termos, caracterizando a autoconsciência em sua determinação independente e universal, oriunda da posição do senhor, e dependente do mundo e singular, referente à posição do servo. Trata-se 
da autoconsciência trabalhadora que suprassume essas posiçôes opostas, ao formar as coisas do mundo, sustentando-se na relação que ainda estabelece com ele e em sua necessidade de satisfação.

Ora, nossa pretensão foi compreender, segundo a leitura de Labarrière, a lógica que organiza as experiências fenomenológicas da consciência. Conforme o autor, encontramos, nessa figura do senhor e do servo, o mesmo princípio que direciona o desenvolvimento do pensamento na Doutrina da Essência da Ciência da Lógica, mais precisamente nas determinaçóes-dareflexão focalizadas na forma de reflexão ponente (setzende Reflexion), reflexão exterior (äusserliche Reflexion) e reflexão determinante (bestimmende Reflexion). No final dessa figura, portanto, encontraremos uma aproximaçáo ao resultado da reflexão determinante (bestimmende Reflexion).

No final dessa figura, verificamos que a unilateralidade da relação de independência e dependência entre o senhor e o servo não levou à estrutura do reconhecimento da autoconsciência como sendo em-si-e-para-si para uma outra autoconsciência também em-si-e-para-si. Retomando a lógica por trás da consciência, notamos as determinaçóes da reflexão exterior (äusserliche Reflexion) no processo fenomenológico da figuras do senhor e do servo, movimento de diferenciação das autoconsciências, efetivado na relação intersubjetiva.

A reflexão determinante (bestimmende Reflexion) da Lógica, unidade da reflexão ponente (setzende Reflexion) e da reflexão exterior (äusserliche Reflexion), é a relação imediata a outro, mas também é a relação a outro refletido em si. É uma relação refletida em si mesma, de modo que o ser posto é reflexão em si mesmo. A reflexão determinante (bestimmende Reflexion) corresponde à volta completa em si mesmo. A resolução da figura do senhor e do servo não vai nos apresentar essa estrutura de reflexáo autodeterminada, de maneira a ser uma determinação que é causa de si mesmo.

No final da figura, temos um novo termo, a autoconsciência trabalhadora, que não é a eliminação absoluta das posiçóes do senhor e do servo, mas a suprassunção destas em unidade que tem em si a independência e a ligação com o mundo objetivo pelo trabalho. Aproximamo-nos, por isso, de um novo fundamento que é posto na sequência da lógica da identidade para a diferença, onde, nesse momento, se identificam em uma unidade a identidade e a diferença. 
COSTA, André Oliveira; BAVARESCO, Agemir. The logical movement of the Hegelian figure of the master and the servant. Trans/Form/Ação, Marília, v. 36, n. 1, p. 37-60, Jan./ Abril, 2013.

\begin{abstract}
This paper aims to discuss the logic that underlies the master-servant dialectic. Jean-Pierre Labarrière categorically claims that there is a logic underlying the movement of the consciousness. The fundamental issue at stake is this: What is the logic that regulates the movement of the consciousness of the self, which culminates in its unity in the moment of reason? The hypothesis advanced here, following Labarrière's suggestions, is that the logic that lies "behind the consciousness" in this figure in Phenomenology of the Mind, is the same logic that Hegel presents in the doctrine of essence in the Science of Logic. The central goal of the present work is to make explicit the logical categories of the doctrine of essence, and to follow their unfolding.
\end{abstract}

KEYWORDS: Hegel. Labarrière. Logic. Master and servant. Acknowledgment. Doctrine of essence.

\title{
REFERÊNCIAS
}

HEGEL, G.W.F. (1807). Fenomenologia do Espírito. Tradução de Paulo Meneses. 2. ed. Petrópolis: Vozes, 2003.

. (1812) Ciencia de la Logica. Tradução de Augusta e Rodolfo Mondolfo. 2. ed. Buenos Aires: Solar, 1968.

HYPPOLITE, J. (1946). Gênese e estrutura da Fenomenologia do Espirito de Hegel. Tradução de Silvio Rosa Filho. 2. ed. São Paulo: Discurso Editorial, 1999.

KOJÈVE, A. (1947). Introdução à leitura de Hegel. Tradução de Estela dos Santos Abreu. Rio de Janeiro: EDUERJ, 2002.

LABARRIÈRE, P.-J. Introdution à une lecture de la Phénoménologie de l'Esprit. Paris: Aubier, 1979.

; JARCZYK, G. Hegeliana. Paris: Presses Universitaires de France, 1986.

- Les premiers combats de la Reconnaissance. Maîtrise et servitude dans la «Phénoménologie de l'Esprit» de Hegel. Paris: Aubier-Montaigne, 1987.

. De Kojève à Hegel: 150 ans de pensée hégélienne en France. Paris: Albin Michel, 1996.

Recebido em: 10.05.2012

Aceito em: 01.09.2012 
COSTA, A. O.; BAVARESCO, A. 